\title{
O ESTATUTO DA CIDADE E A OBRIGATORIEDADE DO PARCELAMENTO, EDIFICAÇÃO OU UTILIZAÇÃO COMPULSÓRIOS
}

The City Statute and the compulsory parcelling, building or utilisation

\section{Daniel Gaio}

danielgaio72@yahoo.com.br

Professor de Direito Urbanístico e Ambiental da Universidade Federal de Minas Gerais. Membro do Corpo Permanente do Programa de Pós-Graduação em Direito/UFMG. Líder do Grupo de Pesquisa e Extensão RE-HABITARE (CNPq).

Doutor em Direito pela PUC/Rio.

\section{RESUMO}

O instrumento do parcelamento, edificação ou utilização compulsórios sempre foi considerado pela literatura e pelos movimentos populares como uma das principais apostas de combate à especulação imobiliária nas cidades. Quando finalmente foi aprovado o Estatuto da Cidade - que regulamentou o capítulo da política urbana - , aos poucos se percebeu que a correlação de forças políticas dificultou a aplicabilidade de quaisquer instrumentos que pudessem concretizar a função social da propriedade. Em oposição a uma interpretação reducionista, este artigo procura demonstrar que o Estatuto da Cidade tem natureza de norma geral e vinculante, especialmente no que se refere ao plano diretor municipal. A partir desta premissa, propõe-se que a análise da obrigatoriedade do instrumento do parcelamento, edificação ou utilização compulsórios seja condicionada à existência de um fundamento material relacionado ao artigo $2^{\circ}$ do Estatuto da Cidade, bem como às circunstâncias fáticas delineadas em um caso concreto.

Palavras-chave: Estatuto da Cidade. Parcelamento, edificação ou utilização compulsórios. Função social da propriedade. Reforma urbana. Direito à moradia.

\section{ABSTRACT}

The instrument of compulsory parcelling, building and utilisation has always been considered by literature and by popular movements as one of the main bets to combat real estate speculation in cities. When the City Statute was finally approved — which regulated the chapter on urban policy —, little by little it was realized that the correlation of political forces made it difficult to apply any instruments that could fulfill the social function of property. As opposed to a reductionist interpretation, this article seeks to demonstrate that the City Statute has the nature of a general and binding rule, especially with regard to the municipal master plan. Based on this premise, it is proposed that the analysis of the obligatory of the instrument of compulsory parcelling, building and utilisation is conditioned to the existence of a material basis related to article 2 of the City Statute, as well as to the factual circumstances outlined in a specific case.

Keywords: City Statute. Compulsory parcelling, building or utilisation. Social function of property. Urban reform. Right to housing. 


\section{INTRODUÇÃO}

Para que se possa analisar a obrigatoriedade do parcelamento, edificação ou utilização compulsórios propõe-se preliminarmente discorrer acerca da relevância deste instrumento para o projeto/ plataforma da reforma urbana. Em virtude do recorte do objeto de análise, a narrativa se circunscreverá a um breve histórico deste instrumento e sua relevância para a construção do Estatuto da Cidade.

Em seguida serão apresentadas distintas concepções do que seja o conteúdo normativo do Estatuto da Cidade (caráter reducionista ou vinculativo), incluindo-se as repercussões sociais e urbanísticas. Ao adotar a concepção vinculativa do Estatuto da Cidade - em especial do seu artigo $2^{\circ}$ - , torna-se necessária a elaboração de pressupostos que permitam caracterizar a obrigatoriedade do parcelamento, edificação ou utilização compulsórios. A metodologia utilizada foi de natureza jurídico-dogmática, com vistas à investigação e compreensão de conteúdo legislativo e doutrinário do assunto elegido, por meio do raciocínio dedutivo.

\section{UM BREVE HISTÓRICO SOBRE O SIGNIFICADO DO ESTATUTO DA CIDADE PARA UM PROJETO DE REFORMA URBANA}

As resistências a um projeto de cidade excludente atravessaram o século 20, mas foi a partir da década de 1960 que se iniciou uma articulação mais orgânica sobre a necessidade de se implementar a reforma urbana no Brasil - a qual não se confunde com práticas de renovação e/ou reestruturação urbana baseadas no modelo "Haussmann", tampouco com pequenos avanços institucionais na previsão e ou implementação de direitos às classes mais pobres na cidade. O sentido de reforma urbana aqui empregado se relaciona com mudanças na estrutura fundiária socialmente excludente, ou seja, algo que seja capaz de reduzir sensivelmente as desigualdades sociourbanísticas existentes.

Foi com este propósito que, desde o Seminário de Habitação e Reforma Urbana (1963) — realizado em duas etapas nos municípios de Petrópolis (RJ) e de São Paulo (BONDUKI; KOURY, 2010) - aos poucos foi se desenvolvendo a ideia de que a criação de um marco regulatório urbanístico seria um pressuposto fundamental para a democratização do solo urbano, sobretudo no que se refere à moradia $^{2}$ social. Sua Resolução Final estabeleceu como questão central atribuir à moradia o status de direito fundamental, exigindo que se conformasse o direito de propriedade por meio de um conjunto de medidas estatais visando à justa utilização do solo urbano (IPASE; IAB, 1963). A regulação da terra urbana se baseava, dentre outras coisas, na capacidade de financiamento dos planos de habitação social a serem implementados, sobretudo por meio do imposto da habitação, que incidiria sobre: i) o registro de loteamentos urbanos; ii) a transferência de lotes; iii) a transferência de mais de $100 \mathrm{~m}^{2}$ de área construída; e iv) a não utilização de imóveis urbanos (IPASE; IAB, 1963).

O Golpe Militar de 1964 arrefeceu as articulações em prol da reforma urbana, mas não esvaziou totalmente o debate e a propostas para que o Poder Público estabelecesse mecanismos tendentes a reduzir a desigualdade - que, aliás, é intrínseca aos planos urbanísticos (CORREIA, 1998, p. 19). Na década de 1970 inúmeros urbanistas, juristas e gestores públicos defenderam que os instrumentos ur-

\footnotetext{
1 Um dos primeiros a descrever o "método Haussmann" foi Engels entre 1872 e 1873 (ENGELS, 2015, p. 104) ao se referir às remoções de populações pobres de áreas centrais em função do embelezamento e saúde pública. Para uma perspectiva mais atual deste modelo/método, ver Harvey, 2014, p. 35-36.

2 Moradia e habitação são tomados como sinônimos neste texto.
} 
banísticos deveriam possibilitar uma divisão mais equitativa entre todos os proprietários de imóveis urbanos (MOREIRA et. al., 1975, p. 08).

Mas foi por meio da Carta de Embu — produzida em fins de 1976 por diversos juristas e planejadores urbanos - que a ideia do solo criado e da transferência do direito de construir ganhou visibilidade nacional e forte adesão na comunidade acadêmica. Baseava-se o documento na implantação de um coeficiente único para todos os terrenos urbanos, sendo que toda edificação acima desse patamar deveria ser considerada solo criado, exigindo-se dos proprietários contrapartidas pelo acréscimo da demanda por equipamentos públicos - os quais deveriam ser custeados por quem pleiteava o benefício (LIRA, 1987, p. 57).

Inegavelmente influenciada pelas propostas defendidas pela Carta de Embu, a Comissão Nacional de Regiões Metropolitanas e Política Urbana (CNPU) - vinculada à Secretaria de Planejamento da Presidência da República - apresentou em 1977 o Anteprojeto de Lei de Desenvolvimento Urbano (O ANTEPROJETO, 1977), cujo conteúdo representava avanços na satisfação dos interesses da coletividade, tais como: i) condicionamento do direito de construir à função social da propriedade (art. $\left.1^{\circ}, \mathrm{IV}\right)$; ii) recuperação das mais-valias (art. 2º, VIII); iii) urbanização compulsória (art. 44 c/c o art. 2 , IV, alíneas "d" e "e"); iv) coeficiente de aproveitamento 1 , sendo permitida a criação de solo com contrapartida à municipalidade quando houver conveniência de um maior adensamento populacional (art. 50 e $\$ 1^{\circ}$ ).

No ano de 1982 o então Conselho Nacional de Desenvolvimento Urbano (CNDU) apresentou o Anteprojeto de Lei de Desenvolvimento Urbano (DOCUMENTO, 1982). Ainda que tenha retrocedido ao não ter previsto o coeficiente único de aproveitamento por Lei federal (art. 29), outros avanços foram apresentados, dentre eles: i) as diretrizes/princípios da justa distribuição dos benefícios e dos ônus decorrentes do processo de urbanização (art. $2^{\circ}$, III, “b”), e do fortalecimento do direito de posse às pessoas de baixa renda (art. $2^{\circ}$, III, “f”); ii) o estabelecimento de limites à expansão urbana; iii) o condicionamento da licença de construir à existência de equipamentos e serviços públicos (art. 31); iv) a previsão de contrapartida ao Poder Público em virtude de mudança dos parâmetros urbanísticos (art. 33); v) a edificação compulsória (art. 34).

Algumas das medidas acima referidas que possibilitariam um maior controle do Estado sobre a utilização do solo urbano foram duramente contestadas pelo mercado imobiliário (REFORMA, 1982, p. 16), de modo que o Projeto de Lei de Desenvolvimento Urbano enviado pelo Governo Federal ao Congresso Nacional em 1983 (A LEI, 1983, p. 15) trouxe vários retrocessos com o objetivo de desfazer a ideia de que o mesmo seria socializante (PARA CNDU, 1983, p. 28), destacando-se o deslocamento da regulação para o poder local. Dessa forma, enquanto alguns mecanismos deixam de ter um condicionamento prévio estabelecido pelo legislador federal - como a ausência de contrapartida em decorrência da alteração dos parâmetros urbanísticos —, enquanto outros somente seriam aplicados se houvesse uma deliberação do legislador municipal (ex: o município poderá condicionar a licença de construir à existência ou à programação de equipamentos urbanos e comunitários — art. 5º o município poderá determinar o parcelamento e a edificação compulsórios - art. 29).

Mesmo com todos os recuos normativos relacionados à plataforma da reforma urbana, o Projeto de Lei 775/83 teve forte resistência dos setores empresariais relacionados ao mercado de solos e da 
construção civil, de modo que a sua aprovação apenas ocorresse no ano de $2001^{3}$. Registra-se que o texto final contemplou a incorporação de instrumentos como o solo criado e as operações urbanas os quais foram propostos pelas entidades imobiliárias (DE GRAZIA, 2002, p. 30-31).

Apesar dos referidos retrocessos em relação à proposta original, a promulgação do Estatuto da Cidade (Lei 10.257/01) - a primeira normativa nacional de desenvolvimento urbano - foi intensamente comemorada pelo Fórum Nacional de Reforma Urbana em um contexto histórico de maior confiança nas instituições públicas após o processo de redemocratização e das promessas daí advindas. O otimismo com o Estatuto da Cidade igualmente decorreu das experiências exitosas de orçamento participativo (Porto Alegre, Santo André e Belo Horizonte); e da crença na institucionalidade para efetivar a reforma urbana foi reforçada pela presença de governantes com projetos de esquerda em várias capitais do país desde o final da década de 1980 (COSTA, 2012, p. 171).

Os conteúdos programáticos defendidos por estas gestões em grande parte correspondiam à plataforma dos movimentos sociais urbanos: política habitacional a fundo perdido ou com fortes subsídios; acesso à terra urbanizada; habitabilidade; cumprimento da função social da propriedade com a eliminação dos grandes vazios urbanos ${ }^{4}$; recuperação das mais-valias urbanísticas; participação popular efetiva nos processos decisórios. Entretanto, a aprovação do Estatuto da Cidade não refletiu os resultados esperados no espectro da reforma urbana, sobretudo em virtude da combinação entre dois elementos: o condicionamento da efetividade dos instrumentos da política urbana à edição de leis municipais; e a correlação de forças locais favoráveis ao mercado imobiliário ${ }^{5}$.

As dificuldades não se resumem ao campo da política, como se verá a seguir, a interpretação reducionista do conteúdo normativo do Estatuto da Cidade mitiga ainda mais a efetividade dos instrumentos de política urbana relacionados à redução das desigualdades na cidade.

\section{A INTERPRETAÇÃO REDUCIONISTA DO CONTEÚDO NORMATIVO DO ESTATUTO DA CIDADE E A EXCLUSÃO SOCIOURBANÍSTICA}

As estratégias de procrastinação de instrumentos de reforma urbana foram uma marca do Estatuto da Cidade. Com algumas exceções, como a obrigatoriedade do Plano Diretor — aliás já determinada pela Constituição Federal (art. 182, $\$ 1^{\circ}$ ) —; a garantia de participação popular; os instrumentos de regularização fundiária (usucapião e concessão de uso especial - MP 2.220/01); e as situações específicas descritas nos artigos 42-A e 42-B da Lei 10.257/01, em geral o Estatuto da Cidade não estabeleceu de modo expresso instrumentos urbanísticos vinculativos à gestão do território.

Pelo fato da grande maioria dos instrumentos de política urbana terem sido normatizados com o verbo "poderá", é ainda majoritária a interpretação de que boa parte dos instrumentos do Estatuto da Cidade foram ali dispostos como uma espécie de caixa de ferramentas aos municípios, cabendo a estes escolherem a conveniência de sua aplicação. O próprio artigo 42 da Lei 10.257/01 reforça esse entendimento ao prever um conteúdo mínimo ao Plano Diretor, incluindo, dentre outros, mecanismos como a operação urbana consorciada. Por razões óbvias, não é possível exigir que este instrumento seja

3 Para informações mais completas acerca da tramitação legislativa do Estatuto da Cidade ver, De Grazia, 2002.

4 Conforme Cardoso (2008, p. 05) o debate sobre os vazios urbanos aparece no Brasil na década de 1970. Entende-se aqui como vazios urbanos os imóveis não edificados, subutilizados ou não utilizados. Para a definição de imóvel subutilizado, ver o artigo $5^{\circ}, \S 1^{\circ}$, I, Lei 10.257/01.

5 Embora a constatação desse fato seja mais nítida a partir da década de 2000, anteriormente Maricato (1994, p. 314) já alertava sobre a dificuldade de implementar as propostas de reforma urbana. 
obrigatório para todos os municípios cuja feitura do plano diretor seja coercitiva, ou seja, desafiando a lógica do que seja um conteúdo mínimo a ser observado.

Embora a interpretação reducionista do Estatuto da Cidade não seja a única causa das desigualdades sociourbanísticas, não há dúvidas de que a adoção da tese da não vinculatividade colaborou decisivamente para o esvaziamento de quaisquer instrumentos que possam afetar de modo mais significativo os interesses econômicos dos setores que exploram o solo urbano. É o que demonstrou a extensa pesquisa sobre a efetividade do Plano Diretor nos municípios brasileiros após o Estatuto da Cidade completar dez anos. Foram analisados 526 relatórios municipais, 26 relatórios de estudo de caso, 27 relatórios estaduais e um relatório nacional (SANTOS JÚNIOR; SILVA; SANT'ANA, 2011, p. 21), e os resultados da pesquisa em relação à reforma urbana são decepcionantes, como apontam Oliveira e Biasotto (2011, p. 95):

(...) de maneira geral, os planos diretores pós-Estatuto da Cidade pouco ou nada avançaram na promoção do acesso à terra urbanizada. Embora a grande maioria dos planos tenha incorporado os princípios e diretrizes do Estatuto - o que, certamente, não é um fato insignificante -, raramente essas orientações se refletiram nos zoneamentos, nos parâmetros urbanísticos definidos, na regulamentação dos instrumentos de política fundiária ou na definição de políticas e medidas voltadas para promover a democratização do acesso à terra urbanizada e bem localizada.

Embora seja indispensável a existência de dados mais completos e atualizados acerca do acesso à moradia adequada ${ }^{6}$ - incluindo-se os serviços e equipamentos públicos, e mobilidade - , alguns indicadores permitem aferir que desigualdade sociourbanística tem aumentado, como a elevação do déficit habitacional de 83,4\% para 88,1\% na faixa de 0 a 3 salários mínimos entre 2013 e 2019 (FUNDAÇÃO JOÃO PINHEIRO, 2016, p. 35; e FUNDAÇÃO JOÃO PINHEIRO, 2021, p. 144). Também é bastante representativa a estimativa realizada pelo IBGE (2020) acerca da quantidade de domicílios ocupados em aglomerados subnormais, passando de 3.224.529 em 2010 para 5.127.747 em 2019.

Muitas são as variáveis que desencadeiam o aumento das desigualdades sociourbanísticas, mas não se pode desconsiderar que contribui para este quadro a baixa efetividade dos instrumentos do Estatuto da Cidade no que diz respeito ao cumprimento dos princípios da função social da propriedade e da cidade.

\section{O CARÁTER VINCULATIVO DO ARTIGO 2 DO ESTATUTO DA CIDADE}

Diferentemente da interpretação reducionista referida no tópico anterior, a análise do artigo $2^{\circ}$ da Lei 10.257/01 a partir de uma caracterização principiológica altera significativamente a sua força jurídica, por consequência a configuração e a efetividade de seus dispositivos.

Pelo fato do Estatuto da Cidade ser matéria de direito urbanístico, de acordo com o sistema constitucional de repartição de competências legislativas, a Constituição Federal estabelece a sua configuração como norma geral (art. 24, I, e $\$ 1^{\circ}, \mathrm{CF}$ ), devendo esta ser observada por estados e municípios. Nesse sentido, precisas são as palavras de Moreira Neto (1988, p. 158) ao conceituar as normas gerais logo após a promulgação da Constituição Federal:

6 Cita-se, a título de exemplo a não realização do Censo de 2020 pelo IBGE. 
Temos fixadas as seguintes características da norma geral: são principiológicas, nacionais e limitativas.

Que as normas gerais tenham natureza de princípios, como vimos, parece ser entendimento discrepante da boa doutrina.

Tal como as normas-princípios, com efeito, por se tratarem de "regras jurídicas gerais", na expressão de PONTES DE MIRANDA, têm por função estabelecer diretrizes para obrigar o grau de decisão subseqüente, porém não só devem ser ela observadas pelo legislador, na edição de norma legal derivada, como pelo aplicador, na ação do Estado ou dos indivíduos.

No caso do capítulo da Política Urbana da Constituição Federal há outra particularidade: atribuiu-se a uma lei federal a definição de diretrizes gerais para a política de desenvolvimento urbano (art. 182, caput, $\mathrm{CF}^{7}$ ), de modo que o Estatuto da Cidade assume as características de uma lei geral de direito urbanístico (SILVA, 2018, p. 67).

Isso significa que o Estatuto da Cidade tem a função de definir o conteúdo e conferir exequibilidade ou aplicabilidade prática ao capítulo da política urbana da Constituição Federal, seja regulando os requisitos e os seus contornos jurídicos, seja detalhando os pormenores de execução que contribuem para a sua plena operatividade ${ }^{8}$.

Tendo em vista que a integralidade dos valores constitucionais deve ser protegida, deve-se buscar a máxima efetividade ${ }^{9}$ das normas previstas pelos artigos 182 e 183 (CF). Ademais, no caso da configuração constitucional da propriedade urbana, vislumbra-se nitidamente a relação entre a funcionalização da propriedade e a realização de valores sociais e existenciais (TEPEDINO, 2004, p. 309), configurando-se uma correlação expressa entre direitos e deveres (ANDRADE, 2007, p. 168-170). Por consequência, ainda que o princípio da função social da propriedade tenha aplicabilidade imediata em várias situações concretas (RODOTÁ, 1990, p. 254) ${ }^{10}$, é indiscutível que há um dever de atuação por parte do legislador infraconstitucional em materializar os direitos sociais na cidade.

Portanto, por força dos artigos 24 e 182 (CF), o caráter vinculante do Estatuto da Cidade é atribuído diretamente pela Constituição Federal. Desse modo, o conjunto das normas da Lei 10.257/01 (diretrizes gerais; instrumentos da política urbana; plano diretor; gestão democrática da cidade; e disposições gerais) são impositivas e vinculantes ${ }^{11}$, sobretudo aos municípios - que são responsáveis pela elaboração e execução do Plano Diretor ${ }^{12}$.

Igualmente o Estatuto da Cidade reconhece esse vínculo de sujeição do Plano Diretor às diretrizes/princípios da Lei 10.257/01, como se vê a seguir:

Art. 39. A propriedade urbana cumpre sua função social quando atende às exigências fundamentais de ordenação da cidade expressas no plano diretor, assegurando o atendimento das necessidades

“(...) a política de desenvolvimento urbano, executada pelo Poder Público municipal, conforme diretrizes gerais fixadas em lei, tem por objetivo ordenar o pleno desenvolvimento das funções sociais da cidade e garantir o bem-estar de seus habitantes”.

8 Para um maior detalhamento desses conceitos, cf. Novais, 2003, p. 172-183.

9 Adere-se, nesse particular, à concepção de efetividade defendida por Luís Barroso, segundo o qual “(...) a efetividade significa, portanto, a realização do Direito, o desempenho concreto de sua função social. Ela representa a materialização, no mundo dos fatos, dos preceitos legais e simboliza a aproximação, tão íntima quanto possível, entre o dever ser normativo e o ser da realidade social". Cf. Barroso, 1996, p. 83.

10 Ver também Silva, 2004, p. 281; Correia, 1997, p. 318-319; e Prata, 1982, p. 175.

11 Esta interpretação pode ser encontrada em: Medauar, 2004, p. 20-23; Sundfeld, 2002, p. 53; Saule Júnior, 2002, p. 84; Gaio, 2015, p. 41; Bruno Filho, 2015, p. 163-164.

12 O plano diretor, aprovado pela Câmara Municipal, obrigatório para cidades com mais de vinte mil habitantes, é o instrumento básico da política de desenvolvimento e de expansão urbana (art. 182, §1, $\mathrm{CF}$ ). 
dos cidadãos quanto à qualidade de vida, à justiça social e ao desenvolvimento das atividades econômicas, respeitadas as diretrizes previstas no art. $2^{\circ}$ desta Lei (grifos nossos).

Independentemente de quais sejam os mecanismos/instrumentos, o Plano Diretor fica obrigado a realizar políticas públicas (normativas ou não) para cumprir o que dispõe no artigo $2^{\circ}$ do Estatuto da Cidade. Tendo em vista a diversidade de situações presentes nos 5.568 municípios brasileiros ${ }^{13}$, a aplicação deste dispositivo legal não ocorrerá de modo uniforme, impondo-se ao intérprete analisar as situações específicas de aplicabilidade.

\section{O PARCELAMENTO, EDIFICAÇÃO OU UTILIZAÇÃO COMPULSÓRIOS E A SUA OBRIGATORIEDADE}

O caráter aberto e principiológico dos conteúdos do artigo $2^{\circ}$ do Estatuto da Cidade possibilitam o enquadramento em uma variada gama de situações concretas, exigindo-se que as políticas públicas - sobretudo municipais - estejam em conformidade com este dispositivo legal. Ainda que haja diversidade fática, ao menos nas grandes cidades brasileiras os problemas são comuns e conhecidos, o que permite identificar os instrumentos do Plano Diretor Municipal que se vinculam ao que dispõe o artigo $2^{\circ}$ (Lei 10.257/01).

Tendo em vista que o uso especulativo da terra urbana é um dos principais obstáculos para a concretização da função social da propriedade e da cidade, os argumentos a seguir expostos são centrados no instrumento do "parcelamento, edificação ou utilização compulsórios" — também conhecido como PEUC —, mas esta metodologia de análise é perfeitamente compatível com os demais instrumentos de política urbana.

\subsection{Uma explicação inicial}

O espraiamento da cidade e a ausência de aproveitamento urbanístico de grande número de imóveis se tornou um grande negócio para determinados proprietários, os quais obtém lucros consideráveis na medida em que são implantadas as redes de infraestrutura e demais investimentos públicos. À medida em que a cidade é transformada e construída, a propriedade agrega valor. Por consequência, o solo urbano mais caro produz mais iniquidade social, pois impõe à maioria da população a condição de morar em territórios com infraestrutura precária, geralmente em áreas periféricas (SINGER, 1982, p. 27).

É necessário enfatizar que o Estado é diretamente responsável por esse processo ${ }^{14}$ : inicialmente o Poder Público cria as condições necessárias para a estruturação e a expansão das cidades, e, posteriormente, o mercado imobiliário potencializa e incrementa as vantagens econômicas de acordo com as necessidades sociais (SMOLKA, 1991, p. 82) ${ }^{15}$. Vale ressaltar ainda que os próprios investimentos privados, na maioria dos casos, dependem da infraestrutura fornecida pelo Estado.

É antiga a mobilização para coibir a especulação imobiliária por parte do Movimento e do Fórum Nacional de Reforma Urbana (SILVA, 1991; e FÓRUM NACIONAL DE REFORMA URBANA, 1990), sem esquecer a proposta de aplicação de um imposto de habitação para os imóveis urbanos não utilizados (IPASE; IAB, 1963).

13 Dados do ano de 2021

14 Para mais detalhes, ver Gaio, 2015, p. 09-18

15 Em alguns casos é a própria valorização das propriedades que move e orienta a localização dos investimentos públicos. Cf. Maricato, 2000, p. 157-158. 
Com esse propósito, o instrumento do parcelamento, edificação ou utilização compulsórios se tornou uma das principais bandeiras da reforma urbana, mas também um discurso institucional de racionalidade na ocupação do território - como se comprova pelas proposições realizadas no âmbito federal: i) Anteprojeto de Lei de Desenvolvimento Urbano/Comissão Nacional de Política Urbana (O ANTEPROJETO, 1977); ii) Anteprojeto de Lei de Desenvolvimento Urbano/Conselho Nacional de Desenvolvimento Urbano (DOCUMENTO, 1982); iii) Projeto de Lei de Desenvolvimento Urbano/ Presidência da República (A LEI, 1983, p. 15). Mas foi a Constituição Federal de 1988 que inaugurou a positivação o parcelamento, edificação ou utilização compulsórios (art. 182, \$4º), sendo posteriormente regulamentado pelo Estatuto da Cidade (art. $5^{\circ}$ a $8^{\circ}$, Lei 10.257/01).

\subsection{As hipóteses de obrigatoriedade do parcelamento, edificação ou utilização compulsórios}

Tendo em vista que o parcelamento, edificação ou utilização compulsórios foi regulado pelo texto constitucional, impõe-se que a sua análise se inicie a partir do que dispõe o artigo $182, \$ 4^{\circ}(\mathrm{CF})$ : "É facultado ao poder público municipal, mediante lei específica para área incluída no plano diretor, exigir, nos termos da lei federal, do proprietário do solo urbano não edificado, subutilizado ou não utilizado que promova seu adequado aproveitamento".

Em uma primeira e rápida leitura deste dispositivo chama a atenção o termo "facultado", o que permitiria supor que a decisão acerca da aplicação do referido mecanismo caberia exclusivamente ao ente municipal. Contudo, ao estabelecer que os limites da sua aplicação serão regrados "nos termos da lei federal" a Constituição Federal remeteu a conformação deste instituto à normativa regulamentadora, qual seja, o Estatuto da Cidade.

Por sua vez, o Estatuto da Cidade não tornou obrigatória a aplicação do parcelamento, edificação ou utilização compulsórios para todos os municípios (art. 5º Lei 10.257/01), mas expressamente previu que a propriedade urbana cumpre sua função social quando atende às exigências fundamentais de ordenação da cidade expressas no plano diretor, respeitadas as diretrizes previstas no art. $2^{\circ}$ (art. 39, Lei 10.257/01).

Portanto, se as determinações do artigo $2^{\circ}$ do Estatuto da Cidade vinculam o plano diretor municipal, especialmente no que diz respeito à concretização da função social da propriedade, torna-se necessário identificar os conteúdos da referida normativa que se relacionem com a funcionalização dos imóveis urbanos, e, por consequência, com o parcelamento, edificação ou utilização compulsórios.

Inicialmente deve-se advertir que há um liame entre os conteúdos do artigo $2^{\circ}$ do Estatuto da Cidade, de modo que a sua interpretação deve ser realizada no seu conjunto, a começar pela indissociabilidade entre os princípios da função social da cidade e o da propriedade (art. $2^{\circ}$, caput, Lei 10.257/01), bem como do destaque dado ao direito à terra urbana e à moradia como elementos essenciais do direito a cidades sustentáveis (inciso I, art. $2^{\circ}$, Lei 10.257/01). Em outras palavras, a concretização do direito à terra urbana e à moradia - que se constituem o eixo estruturante da função social da cidade -, é diretamente proporcional à efetivação do princípio da função social da propriedade.

Outra inter-relação direta com o instrumento do parcelamento, edificação ou utilização compulsórios se dá quando o inciso VI, alínea "a” do artigo 2 (Lei 10.257/01) estabelece que a ordenação do solo deve evitar "a retenção especulativa de imóvel urbano, que resulte na sua subutilização ou não 
utilização". É notório que esta prática encarece o preço dos terrenos, dificultando o direito à terra urbana e à moradia; além do fato de que a existência de vazios urbanos ocasiona infraestruturas mais extensas e custosas, afora os imensos prejuízos sociais em virtude do aumento dos deslocamentos urbanos.

A retenção especulativa do solo igualmente se relaciona com o planejamento e distribuição das atividades na cidade e seus efeitos negativos no meio ambiente, e com a expansão urbana compatíveis com os limites da sustentabilidade ambiental, social e econômica (incisos IV e VIII, art. $2^{\circ}$, Lei 10.257/01). Com efeito, há uma relação de causa e efeito entre a especulação imobiliária e o espraiamento urbano, com reflexos ambientais indiscutíveis, como o maior consumo energético, que se dissipa em forma de calor e de poluição atmosférica (RUEDA, 1997); além de aumentar a impermeabilização e a retirada da vegetação.

Em última análise, os vazios urbanos violam inúmeros princípios previstos no artigo $2^{\circ}$ do Estatuto da Cidade - aliás, igualmente garantidos pela Constituição Federal —, nomeadamente os princípios da função social da propriedade e da cidade; o direito à moradia; e a sustentabilidade. Por consequência, restam estabelecidos os fundamentos materiais balizadores da inter-relação entre os danos à coletividade decorrentes da retenção especulativa e a não concretização do instrumento do parcelamento, edificação ou utilização compulsórios.

Para além do explícito e indiscutível fundamento material previsto no artigo $2^{\circ}$ do Estatuto da Cidade, a obrigatoriedade de previsão legal e posterior aplicação do parcelamento, edificação ou utilização compulsórios por meio do plano diretor municipal requer ainda a análise das circunstâncias concretas que a justifiquem. Nesse sentido, embora se exija uma investigação acerca da situação sociourbanística específica em cada município ${ }^{16}$, depreende-se que a existência de um déficit habitacional cumulada com vazios urbanos é causa justificante para a cogente aplicação do parcelamento, edificação ou utilização compulsórios. Um bom indicativo é a estimativa de déficit habitacional em áreas urbanas para 2015 foi de 5.572.700 domicílios, o total de domicílios vagos em áreas urbanas é de 6.350.010 (FUNDAÇÃO JOÃO PINHEIRO, 2018, p. 33 e 38).

O mesmo raciocínio se aplica à existência de um espraiamento da cidade combinado com a retenção especulativa da terra urbana, já que este modelo de expansão horizontal de cidade contribui significativamente para o déficit habitacional e ocasiona impactos ambientais desnecessários - poluição; destruição de áreas verdes, da paisagem e de sítios arqueológicos; e degradação de áreas centrais degradadas (GAIO, 2020, p. 144). Não há muita dificuldade em comprovar tais fatos, já que as cidades brasileiras são repletas de grandes vazios, loteamentos aprovados e não adensados, e ampliações de perímetro urbano especulativas.

\section{CONSIDERAÇÕES FINAIS}

Uma das riquezas do Direito são as suas múltiplas possibilidades interpretativas. Inúmeros pareceres e teses são construídos com sólidos argumentos, em geral capazes de convencer leitores e intérpretes do direito habituados com explicações formais e lógicas do ponto de vista do sistema jurídico.

Mas há limites para a criatividade e defesa de interesses particulares, ainda que legítimos, a ordem constitucional exige que os seus valores sejam otimizados em todas as suas potencialidades

16 É indispensável que o poder público municipal tenha dados atualizados acerca da situação dos imóveis urbanos, garantida a transparência e o controle social. 
(CANOTILHO, 2003, p. 1240), o que significa dar sentido e concretude aos princípios da função social da propriedade e da cidade, especialmente por intermédio do parcelamento, edificação ou utilização compulsórios.

Além da sua força normativa em si, a função social da propriedade não pode ser considerada uma mera abstração em relação ao mundo real. A dignidade de milhões de pessoas depende diretamente das condições de acesso à moradia e terra urbana nas cidades. Portanto, ao invés de naturalizar a pobreza e a exclusão social, é imperativo ético e jurídico que o conteúdo do plano diretor municipal contemple instrumentos que assegurem o cumprimento do artigo $2^{\circ}$ do Estatuto da Cidade, tal como o parcelamento, edificação ou utilização compulsórios.

\section{REFERÊNCIAS}

ANDRADE, José Carlos Vieira de. Os direitos fundamentais na Constituição Portuguesa de 1976. $3^{a}$ ed. Coimbra: Almedina, 2007.

O ANTEPROJETO. Jornal da Tarde, maio 1977.

BARROSO, Luís Roberto. O direito constitucional e a efetividade de suas normas. $3^{\text {a }}$ ed. Rio de Janeiro: Renovar, 1996.

BONDUKI, Nabil; KOURY, Ana Paula. Das reformas de base ao BNH: as propostas do Seminário de Habitação e Reforma Urbana. Arquitextos, maio 2010. Disponível em: <http://www.vitruvius.com.br/ revistas/read/arquitextos/10.120/3432>. Acesso em: 06 ago. 2014.

BRUNO FILHO, Fernando Guilherme. Princípios de direito urbanístico. Porto Alegre: Sergio Fabris, 2015.

CANOTILHO, José Joaquim Gomes. Direito constitucional e teoria da Constituição. $7^{\mathrm{a}}$ ed. Coimbra: Almedina, 2003.

CARDOSO, Adauto Lúcio. Vazios urbanos e função social da propriedade. Revista Trimestral de Debate da FASE, nº 116, p. 04-10, abr.-jun. 2008.

PARA CNDU, plano não é socializante. O Estado de São Paulo, São Paulo, 05 maio 1983, p. 28.

CORREIA, Fernando Alves. O plano urbanístico e o princípio da igualdade. Coimbra: Almedina, 1997. CORREIA, Fernando Alves. Problemas actuais do direito do urbanismo em Portugal. Revista do Centro de Estudos de Direito do Ordenamento do Urbanismo e do Ambiente. Coimbra, nº 02, p. 09-32, 1998. COSTA, Maria de Fátima Tardin. Ideologia e utopia no ocaso da reforma urbana no Brasil. Rio de Janeiro, 2012. Tese de Doutorado - Programa de Pós-Graduação em Psicologia Social. Universidade do Estado do Rio de Janeiro.

DE GRAZIA, Grazia. Estatuto da cidade: uma longa história com vitórias e derrotas. In: OSÓRIO, Letícia Marques (Org.). Estatuto da Cidade e reforma urbana: novas perspectivas para as cidades brasileiras. Porto Alegre: Sérgio Antonio Fabris, 2002, p. 15-37.

DOCUMENTO. Jornal da Tarde, São Paulo, 27 jan. 1982, p. 16-17. 
ENGELS, Friedrich. Sobre a questão da moradia. Tradução de Nélio Schneider. São Paulo: Boitempo, 2015.

FÓRUM NACIONAL DE REFORMA URBANA. II Fórum Nacional sobre reforma urbana: Carta de princípios sobre o plano diretor. In: DE GRAZIA, Grazia (Org). Plano diretor: instrumento de reforma urbana, Rio de Janeiro: FASE, 1990, p. 89-93.

FUNDAÇÃO JOÃO PINHEIRO - CENTRO DE ESTATÍSTICA E INFORMAÇÕES. Déficit habitacional no Brasil 2013-2014. Belo Horizonte: Fundação João Pinheiro, 2016.

FUNDAÇÃO JOÃO PINHEIRO. Déficit habitacional no Brasil 2015. Belo Horizonte: FJP, 2018.

FUNDAÇÃO JOÃO PINHEIRO. Déficit habitacional no Brasil - 2016-2019. Belo Horizonte: Fundação João Pinheiro, 2021.

GAIO, Daniel. A interpretação do direito de propriedade em face da proteção constitucional do meio ambiente urbano. Rio de Janeiro: Renovar, 2015.

GAIO, Daniel. Cidade compacta e sustentabilidade. In: BRANT, Leonardo Nemer Caldeira; DINIZ, Pedro Ivo Ribeiro (Org.). Agenda 2030 e o desenvolvimento sustentável no contexto latino-americano. Belo Horizonte: CEDIN, 2020, p. 135-148.

HARVEY, David. Cidades rebeldes: do direito à cidade à revolução urbana. São Paulo: Martins Fontes, 2014.

IBGE. Aglomerados subnormais 2019: classificação preliminar e informações de saúde para o enfrentamento à COVID-19, Rio de Janeiro, 18 maio 2020.

IPASE; IAB. Seminário de Habitação e Reforma Urbana. Arquitetura, nº 15, p. 17-24, set. 1963.

A LEI do solo, na íntegra. Jornal da Tarde, São Paulo, 05 maio 1983.

LIRA, Ricardo César Pereira. A propriedade urbanística. Revista Forense, Rio de Janeiro, no 300, p. 53-59, 1987.

MARICATO, Ermínia. Reforma urbana: limites e possibilidades - uma trajetória incompleta. In: RIBEIRO, Luiz Cezar de Queiroz; SANTOR JÚNIOR, Orlando Alves dos (Org.). Globalização, fragmentação e reforma urbana: o futuro das cidades brasileiras na crise. Rio de Janeiro: Civilização Brasileira, 1994, p. 309-325.

MARICATO, Ermínia. As idéias fora do lugar e o lugar fora das idéias: planejamento urbano no Brasil. In: ARANTES, Otília; VAINER, Carlos; MARICATO, Ermínia (Org.). A cidade do pensamento único: desmanchando consensos. Petrópolis: Vozes, 2000, p. 121-192.

MEDAUAR, Odete. Diretrizes gerais. In: MEDAUAR, Odete; ALMEIDA, Fernando Dias Menezes de (Org.). Estatuto da Cidade: Lei 10.257, de 10.07.2001, comentários. 2a ed. São Paulo: RT, 2004, p. 15-40. MOREIRA, Antonio Cláudio Moreira Lima et al. O solo criado. São Paulo: CEPAM, 1975.

MOREIRA NETO, Diogo de Figueiredo. Competência concorrente limitada: o problema da conceituação das normas gerais. Revista de Informação Legislativa. Brasília, nº 100, p. 127-162, out.-dez. 1988. 
NOVAIS, Jorge Reis. As restrições aos direitos fundamentais não expressamente autorizadas pela Constituição. Coimbra: Coimbra, 2003.

OLIVEIRA, Fabrício Leal de; BIASOTTO, Rosane. O acesso à terra urbanizada nos planos diretores brasileiros. In: SANTOS JUNIOR, Orlando Alves; MONTANDON, Daniel Todtmann (Org.). Os planos diretores municipais pós-Estatuto da Cidade: balanço crítico e perspectivas. Rio de Janeiro: Letra Capital: Observatório das Metrópoles: IPPUR/UFRJ, 2011, p. 57-96.

PRATA, Ana. A tutela constitucional da autonomia privada. Coimbra: Almedina, 1982.

REFORMA urbana vista como “forte demais”. O Estado de São Paulo, São Paulo, 29 jan. 1982, p. 16. RODOTÀ. Stefano. Il terrible diritto: studi sulla proprietà privata. 2a ed. Bologna: Società editrice il Mulino, 1990.

RUEDA, Salvador. La ciudad compacta y diversa frente a la conurbación difusa, 30 jun. 1997. Disponível em: <http://habitat.aq.upm.es/cs/p2/a009.html>. Acesso em: 04 set. 2020.

SANTOS JUNIOR, Orlando Alves; SILVA, Renata Helena; SANT'ANA, Marcel Claudio. Introdução. In: SANTOS JUNIOR, Orlando Alves; MONTANDON, Daniel Todtmann (Org.). Os planos diretores municipais pós-Estatuto da Cidade: balanço crítico e perspectivas. Rio de Janeiro: Letra Capital: Observatório das Metrópoles: IPPUR/UFRJ, 2011, p. 13-26.

SAULE JÚNIOR, Nelson. Estatuto da Cidade e o plano diretor - possibilidades de uma nova ordem legal urbana justa e democrática. In: OSÓRIO, Letícia Marques (Org.). Estatuto da Cidade e reforma urbana: novas perspectivas para as cidades brasileiras. Porto Alegre: Sérgio Antonio Fabris, 2002, p. 77-119.

SILVA, Ana Amélia da. Reforma urbana e o direito à cidade. São Paulo: Pólis, 1991.

SILVA, José Afonso da. Curso de direito constitucional. 23ª ed. São Paulo: Malheiros, 2004.

SILVA, José Afonso da. Direito urbanístico brasileiro. $8^{\mathrm{a}}$ ed. São Paulo: Malheiros, 2018

SINGER, Paul. O uso do solo urbano na economia capitalista. In: MARICATO, Ermínia (Org.). A produção capitalista da casa (e da cidade) no Brasil industrial. São Paulo: Alfa-Omega, 1982, p. 21-36.

SMOLKA, Martim. Precio de la tierra y valorización inmobiliaria urbana: esbozo para uma conceptualización del problema. Revista Interamericana de Planificacion. Bogotá, nº 60, p. 70-89, dic. 1991.

SUNDFELD, Carlos Ari. O Estatuto da Cidade e suas diretrizes gerais. In: DALLARI, Adilson Abreu; FERRAZ, Sérgio (Org.). Estatuto da Cidade (Comentários à Lei Federal 10.257/01). São Paulo: Malheiros, 2002, p. 44-60.

TEPEDINO, Gustavo. Contornos constitucionais da propriedade privada. In: TEPEDINO, Gustavo (Org.). Temas de direito civil. $3^{\text {a }}$ ed. Rio de Janeiro: Renovar, 2004, p. 303-329. 